\title{
Access to dental services and oral health-related quality of life in the context of primary health care
}

\author{
Lucelen Fontoura BASTOS(a) \\ Fernando Neves HUGO(b) \\ Juliana Balbinot HILGERT(b) \\ Débora Deus CARDOZO(c) \\ Alexandre Fávero BULGARELLI(a) \\ Camila Mello dos SANTOS(a) \\ (a) Universidade Federal do Rio Grande do Sul \\ - UFRGS, Collective Health Postgraduate \\ Programme, Porto Alegre, RS, Brazil. \\ (b) Universidade Federal do Rio Grande do \\ Sul - UFRGS, Department of Preventive and \\ Social Dentistry, Porto Alegre, RS, Brazil. \\ (c) Hospital Conceição, Porto Alegre, \\ RS, Brazil.
}

Declaration of Interests: The authors certify that they have no commercial or associative interest that represents a conflict of interest in connection with the manuscript.

Corresponding Author:

Lucelen Fontoura Bastos

E-mail: lucelen@gmail.com

https://doi.org/10.1590/1807-3107bor-2019.vol33.0018

Submitted: January 29, 2019

Accepted for publication: June 13, 2019

Last revision: July 16, 2019

\begin{abstract}
The aim of the present study was to evaluate the association between access to oral health care in the Primary Health Care (PHC) and Oral Health-Related Quality of Life (OHRQoL). The present study was a cross-sectional study, and the sample was composed of 412 users living in the areas covered by the public PHC services who visited a health unit for an oral exam or treatment in the last 24 months. Participants in the study responded to a home-based interview with questions that addressed socioeconomic status, behavioral, general health, dental prostheses, access to dental services in the PHC and their OHRQoL as measured by the Oral Health Impact Profile (OHIP-14) instrument. After the interview, a dental examination was performed to count the number of teeth. Chi-square tests, Student's $t$ tests and multivariate analyses were performed using a hierarchical model and a Poisson regression with robust variance to evaluate the association between independent variables and OHRQoL. Access to oral health services in the PHC was statistically associated with OHRQoL, and the estimated prevalence rate was $\mathrm{PR}=1.17$ (CI 95\% 1.00-1.37). In this study, the definition of access was based on the availability of dental consultations on demand. The study identified that lack of access to oral health services offered by the PHC was associated with a higher prevalence of impact on the quality of life of individuals.
\end{abstract}

Keywords: Primary Health Care; Quality of Life; Health Services Accessibility; Oral Health.

\section{Introduction}

It is important to recognize the relationship between oral health and quality of life because the interaction between these two elements impacts the daily life of an individual on functional, social and psychological levels. ${ }^{1,2}$ Studies evaluating Oral Health-Related Quality of Life (OHRQoL) allow a better understanding of the interactions between the perception of oral health, the external environment, individual characteristics, healthrelated behaviors and objective and subjective health. ${ }^{3}$

Sociodental indicators were assembled to allow the analysis of the impact of oral health issues on the quality of life, thus allowing a broader perspective on the diagnosis and treatment of oral health conditions and taking into account the individual's perception of health. ${ }^{4,5}$ The OHIP- 
14 questionnaire is an instrument used to analyze the impact of dental health on quality of life, and several studies found associations between oral health conditions and OHRQoL using the OHIP14. ${ }^{6,7,8,9}$ In addition, the use of tools that assess the individual's experience and perception of his or her health care during a particular procedure may itemize the characteristics of the procedure while also gathering data related to the health of the users. Patient-Reported Outcomes Measures (PROMs) provide information on the efficiency and effectiveness of services, patient satisfaction, and they assess the impact of treatment. ${ }^{10}$ Properly assembled PROM instruments have the potential to generate data that allow comparisons between different care providers, treatments and performance of service providers. ${ }^{11}$

Notwithstanding the several breakthroughs during the process of expansion in recent years, Primary Health Care (PHC) services in Brazil are still struggling to overcome the forceful fragmentation of health actions, services and qualifying care management. ${ }^{12,13}$ Given this context, the discussion of health access becomes more important and is now being approached in a more complex manner since, despite the guarantee of access provided by law, access to public health services is still selective, focused and exclusionary. ${ }^{14}$

With this context in mind, PHC, when seen as a strategy able to provide health services in an equitable and efficient manner and to organize the access to health systems, PHC have the potential to influence the quality of life and to reduce vulnerability as well as health risks of individuals. ${ }^{15,16}$ Several studies have approached the relationship between OHRQoL and clinical variables in different populations. ${ }^{9,17,18,19}$ Nevertheless, the relationship between the characteristics of PHC services, such as access to oral health, and OHRQoL of those who use these services remains unknown. It is necessary to gather data to verify whether the provision of access to dental care through PHC services is related to OHRQoL in order to improve on the outcomes commonly measured, which are based on clinical variables and quality of life, while also understanding the factors related to specific services and to the PHC and their interaction with OHRQoL. Therefore, the objective of the study was to evaluate the association between access to oral health care through the Primary Health Care and OHRQoL.

\section{Methodology}

\section{Ethical approval}

This study was approved by The Research Ethics Committee of Grupo Hospitalar Conceição and the Porto Alegre City Hall (processes 10-120 and 001043203108). The participants were informed about the objectives of the research and were asked to read and sign the informed consent form.

\section{Sample}

This cross-sectional study used data from the study "Validation and application of the PCATool-SB to assess the quality of Primary Care for Oral Health - user version". ${ }^{20}$

The sample size for the original study was defined by a pilot study since there were no data that allowed a sample size calculation. The data were collected from 30 interviews that took place at the PHC services in Porto Alegre to estimate the sample size required to fulfill the validation criteria of the original study, which was based on the Primary Care Assessment Tool (PCATool) (5 respondents per PCATool question). ${ }^{21}$ The estimated sample comprised 412 users of PHC services.

The eligibility criteria of the subjects participating in the study were the following: to be at least 18 years old, to reside in the areas covered by the public PHC network with dental services available, and to have used the health unit for a dental check-up or treatment in the last 24 months. The following criteria were used for the health units: having a dental office, having an oral health team with a dental surgeon and an oral health auxiliary or technician, having a dental surgeon working in the unit for at least 2 years and having a fully booked dental surgeon in the unit where they performed the dental care.

Fifteen health units of the primary health care services of Porto Alegre, which met the inclusion criteria, were selected. After that, census sectors were drawn within the territory of the health units. Within each census sector, family households were randomly selected, and from each household, a user 
meeting the eligibility criteria was interviewed. If the household had more than one adult who met the criteria, one of them was randomly selected. ${ }^{21}$

\section{Researchers' training section}

Data collection took place between October 2011 and May 2013, and the users selected were then interviewed at their homes by previously trained researchers. Students from the health area conducted the interviews at home visits. The training of the interviewers took place before the beginning of the study and consisted of three meetings of 4 hours each, in which participants received guidance on the methodology required for application, manipulation and completion of the questionnaires. A field manual was compiled for the researchers, and during the training, the interviewers conducted simulated interviews. To assess the training, a pilot practice field trip took place in which pairs of researchers administered the questionnaire to each other.

\section{Measures}

Participants in the study responded to an interview addressing socioeconomic status, behavioral and general health, access to dental services in the PHC and OHRQoL (as measured by the OHIP-14 instrument). All stages of the interview occurred in one visit, after which the oral clinical examination was carried out.

A standard questionnaire was used to collect information on socioeconomic status, general health, behavioral health, presence of dental prostheses, and access to dental services. Socioeconomic data included information regarding age (in years), sex, education (in years of study, categorized as $\leq 8$ years and $>8$ years), self-declared color/race (categorized as white and nonwhite) and monthly income (based on the Brazilian minimum wage, which was equivalent to $\mathrm{U} \$ 347.68$, and categorized as $\leq 1$ minimum wage and $>1$ minimum wage).

General health was self-reported. The participants reported the presence of chronic disease when asked the following question: "Do you have any health issue that has lasted or that will probably last more than a year, such as a physical, mental or emotional problem?". The chronic disease was regarded as present when the diseases diabetes mellitus and/or arterial hypertension were reported, and the responses were categorized into present or absent for chronic disease. The habit of smoking was assessed with the following question: "Do you currently smoke cigarettes?". The answers were categorized as yes or no for smoking.

The presence of dental prostheses was assessed through the question "Do you use any kind of prosthesis (bridge, pivot, denture) in the teeth/ upper arch?" and "Do you use any kind of prosthesis (bridge, pivot, denture) in the teeth/lower arch?". The answers were categorized as yes or no for the following variables: uses an upper dental prosthesis and uses a lower dental prosthesis.

The following question was asked to assess the access to the oral health services of the primary health care: "When your health center is open and you have an issue with your mouth or teeth, is there someone that can see you on the same day?", and the possible answers were yes or no.

The OHIP-14 instrument comprises 14 items that assess dysfunction, discomfort and disability attributed to oral health conditions. The possible answers to the items are presented in a five-point Likert scale, ranging from never (0) to always (4) ${ }^{5}$. To assess the impact on quality of life, the answers were dichotomized to the absence of impact (a sum equal to zero) and the presence of impact (when the sum was greater than zero) in the OHRQoL.., 7

After the interview, the individuals were submitted to an oral examination to assess the number of natural teeth found in the oral cavity. The number of teeth was classified as $\leq 20$ teeth or $>20$ teeth. $^{6}$

\section{Statistical analysis}

All analyses were performed using the Statistical Package for Social Sciences (SPSS version 18.0).

A descriptive analysis was used to characterize the sample; means were used for quantitative variables, and percentages were used for qualitative variables. Chi-squared tests were carried out for the categorical variables, whereas for continuous variables, Student's t-test was applied. OHIP-14 reliability was tested by means of the Cronbach's alpha coefficient.

Data analysis was carried out by means of a hierarchical approach based on the conceptual 
framework proposed by Andersen and Davidson. ${ }^{22}$ The model is comprised of variables distributed into the following four blocks: exogenous variables, primary determinants of oral health, health behaviors and oral health conditions (Figure).

The first block of the model in this study comprised exogenous and more distal variables: age, sex and self-declared color/race. In the second block, as intermediate variables, the primary determinants of oral health were found and were represented by income, education and chronic illness. The intermediate variables, from the third block of the analysis, were health behaviors, such as smoking and access to oral health through the PHC system. In the proximal block, which is the fourth block, the variables of oral health outcomes were included: upper dental prosthesis, lower dental prosthesis and number of teeth.

Prevalence ratios (PRs) were estimated using Poisson regression with a robust variance estimator. Initially, the hierarchical approach consisted of univariate Poisson regression models that were used to estimate the relationships between each variable studied and the outcome. Multivariate Poisson regression was then performed within each level. Variables were retained in the subsequent hierarchical levels if $p<0.10$ after adjusting for confounders within their own levels and if hierarchically anterior variables remained associated $(p<0.10)$ with the outcome within their own levels. Finally, only variables that had $p<0.10$ in the previous models were included in the final, fully adjusted model. In the fully adjusted model, the magnitudes of association between the independent variables and the studied outcomes were estimated using prevalence ratios, with $\mathrm{p}<0.05$ indicating significance, and $95 \%$ confidence intervals.

\section{Results}

For this study, 1943 people were asked to participate. A total of 81 residences were visited three different times, and no people were found at home. Six people refused to participate, and 1444 had never used PHC services for oral health appointments, hence failing to meet the study's inclusion criteria. The Cronbach's alpha coefficient for the OHIP-14 assessments was 0.89

Characteristics of the studied participants are shown in Table 1. Of the 412 participants, most were female $(79.8 \%)$, the mean age was $48.3( \pm 16.7)$ years, the predominant color/race was white (59.7\%), and the participants had 8 years or less of education (61.4\%). When the interviewee's individual income was assessed, $58.3 \%$ had a monthly income of less than or equal to the minimum wage. Regarding the access to oral health services in the primary health care system, $56.6 \%$ of the participants reported that they were not seen on the same day when they visited their health unit to address oral or teeth issues. Among the oral health variables, most participants did not use an upper dental prosthesis $(55.8 \%)$ or a lower dental prosthesis $(80.8 \%)$, and when the number of teeth was assessed, the majority of participants had twenty teeth or less (59.3\%). Participants who smoked and reported having a chronic illness accounted for $25.5 \%$ and $37.9 \%$ of the sample, respectively.

As shown in Table 2, the variables number of natural teeth found in the oral cavity and the

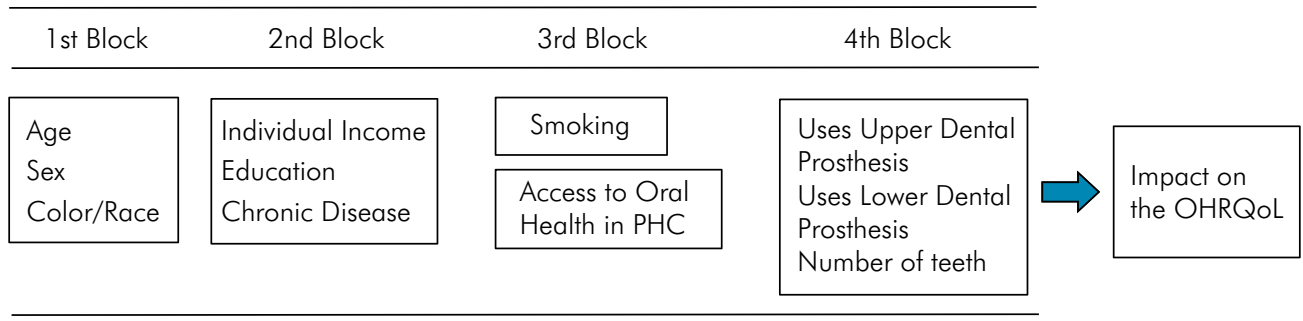

Figure. Theoretical model used in the study. 
Table 1. Characterization of the sample of users of primary health care services in Porto Alegre, Rio Grande do Sul, Brazil, $2013(n=412)$.

\begin{tabular}{|c|c|}
\hline Variables & \\
\hline \multicolumn{2}{|l|}{ Age } \\
\hline In years (DP) & $48.3( \pm 16.7$ \\
\hline \multicolumn{2}{|l|}{ Sex } \\
\hline Male & 79 (20.2\%) \\
\hline Female & $329(79.8 \%)$ \\
\hline \multicolumn{2}{|l|}{ Education } \\
\hline$\leq 8$ years & $253(61.4 \%)$ \\
\hline$>8$ years & $158(38.3 \%)$ \\
\hline \multicolumn{2}{|l|}{ Color/Race } \\
\hline White & $256(59.7 \%)$ \\
\hline Nonwhite & $162(39.3 \%)$ \\
\hline \multicolumn{2}{|l|}{ Individual income } \\
\hline$\leq 1$ minimum wage & $240(58.3 \%)$ \\
\hline$>1$ minimum wage & $172(41.7 \%)$ \\
\hline \multicolumn{2}{|c|}{ Access to oral health in PHC } \\
\hline Yes & $179(43.4 \%)$ \\
\hline No & $233(56.6 \%)$ \\
\hline \multicolumn{2}{|c|}{ Uses upper dental prosthesis } \\
\hline Yes & $182(44.2 \%)$ \\
\hline No & $230(55.8 \%)$ \\
\hline \multicolumn{2}{|c|}{ Uses lower dental prosthesis } \\
\hline Yes & $79(19.2 \%)$ \\
\hline No & $333(80.8 \%)$ \\
\hline \multicolumn{2}{|l|}{ Number of teeth } \\
\hline$\leq 20$ Teeth & $240(59.3 \%)$ \\
\hline$>20$ Teeth & $171(41.7 \%)$ \\
\hline \multicolumn{2}{|l|}{ Chronic disease } \\
\hline Present & $156(37.9 \%)$ \\
\hline Absent & $256(62.1 \%)$ \\
\hline \multicolumn{2}{|l|}{ Smoking } \\
\hline Yes & 105 (25.5\%) \\
\hline No & 307 (74.5\%) \\
\hline
\end{tabular}

*Totals vary due to loss of information.

presence of chronic disease were associated with OHIP-14 outcome. There was a significant association between individuals with 20 teeth or less $(68.8 \%)$ had a significant association with the presence of impact OHRQoL $(p=0.01)$. Furthermore, the presence of
Table 2. Association between the OHIP- 14 outcomes and the characteristics of users of primary health care services in the city of Porto Alegre, Rio Grande do Sul, Brazil, 2013 ( $n=412$ ).

\begin{tabular}{|c|c|c|c|}
\hline \multirow{2}{*}{ Variables } & \multicolumn{2}{|c|}{ OHIP-14 } & \multirow{2}{*}{$p$-value } \\
\hline & No impact & With impact & \\
\hline \multicolumn{4}{|l|}{ Age } \\
\hline In Years (DP) & $46.04 \pm 16.14$ & $49.98 \pm 16.86$ & 0.83 \\
\hline \multicolumn{4}{|l|}{ Sex } \\
\hline Male & $34(43.0 \%)$ & 45 (57.0\%) & 0.29 \\
\hline Female & 119 (36.6\%) & $206(63.4 \%)$ & \\
\hline \multicolumn{4}{|l|}{ Education } \\
\hline$\leq 8$ years & 92 (36.5\%) & $160(63.5 \%)$ & 0.40 \\
\hline$>8$ years & $63(40.6 \%)$ & 92 (59.4\%) & \\
\hline \multicolumn{4}{|l|}{ Color/Race } \\
\hline White & $90(36.8)$ & $154(63.2 \%)$ & 0.70 \\
\hline Nonwhite & $62(38.8 \%)$ & $98(61.2 \%)$ & \\
\hline \multicolumn{4}{|l|}{ Individual income } \\
\hline$\leq 1$ minimum wage & 85 (36.0\%) & $151(64.0 \%)$ & 0.33 \\
\hline$>1$ minimum wage & 70 (40.7\%) & 102 (59.3\%) & \\
\hline \multicolumn{4}{|c|}{ Access to oral health in $\mathrm{PHC}$} \\
\hline Yes & $69(38.5 \%)$ & $110(61.5 \%)$ & 0.83 \\
\hline No & $86(37.6 \%)$ & $143(62.4 \%)$ & \\
\hline \multicolumn{4}{|c|}{ Uses upper dental prosthesis } \\
\hline Yes & $64(35.2 \%)$ & $118(64.8 \%)$ & 0.29 \\
\hline No & 91 (40.3\%) & 135 (59.7\%) & \\
\hline \multicolumn{4}{|c|}{ Uses lower dental prosthesis } \\
\hline Yes & $24(30.4 \%)$ & 55 (69.6\%) & 0.12 \\
\hline No & $131(39.8 \%)$ & 198 (60.2\%) & \\
\hline \multicolumn{4}{|l|}{ Number of teeth } \\
\hline$\leq 20$ Teeth & $53(31.2 \%)$ & 117 (68.8\%) & $0.01^{*}$ \\
\hline$>20$ Teeth & 102 (43.0\%) & 135 (57.0\%) & \\
\hline \multicolumn{4}{|l|}{ Chronic disease } \\
\hline Present & 68 (44.2\%) & $86(55.8 \%)$ & $0.04^{*}$ \\
\hline Absent & 87 (34.3\%) & 167 (65.7\%) & \\
\hline \multicolumn{4}{|l|}{ Smoking } \\
\hline Yes & 40 (38.1\%) & 65 (61.9\%) & 0.97 \\
\hline No & 115 (38.0\%) & 188 (62.0\%) & \\
\hline
\end{tabular}

*Significance by the Chi-squared test.

chronic disease $(55.8 \%)$ was associated with OHRQoL, as measured by the OHIP-14 ( $\mathrm{p}=0.04)$.

In the first block of the analysis, the exogenous variables sex and race did not significantly associated 
Access to dental services and oral health-related quality of life in the context of primary health care

Table 3. Hierarchical analysis - impact on the oral health-related quality of life

\begin{tabular}{|c|c|c|c|c|c|c|c|}
\hline Block & Variables & Crude PR $(95 \% \mathrm{CI})$ & $p$-value & $\begin{array}{c}\text { Adjusted PR* }(95 \% \\
\text { CI) }\end{array}$ & $\mathrm{p}$-value & $\begin{array}{c}\text { Adjusted PR** }(95 \% \\
\text { CI) }\end{array}$ & $\mathrm{p}$-value \\
\hline \multirow{8}{*}{$1 \mathrm{st}$} & Age & & & & & & \\
\hline & In years & $1.00(1.00-1.01)$ & 0.01 & $1.00(1.00-1.01)$ & 0.02 & & \\
\hline & Sex & & & & & & \\
\hline & Female & 1.00 & & 1.00 & & & \\
\hline & Male & $0.89(0.72-1.10)$ & 0.31 & $0.86(0.70-1.07)$ & 0.18 & & \\
\hline & Color/Race & & & & & & \\
\hline & Nonwhite & 1.00 & & 1.00 & & & \\
\hline & White & $1.03(0.88-1.20)$ & 0.70 & $1.01(0.86-1.18)$ & 0.85 & & \\
\hline \multirow{9}{*}{ 2nd } & Individual incor & & & & & & \\
\hline & $>1$ wage & 1.00 & & 1.00 & & 1.00 & \\
\hline & $\leq 1$ wage & $1.10(0.94-1.29)$ & 0.21 & $1.11(0.94-1.30)$ & 0.19 & $1.10(0.93-1.30)$ & 0.22 \\
\hline & Education & & & & & & \\
\hline & $>8$ years & 1.00 & & 1.00 & & 1.00 & \\
\hline & $\leq 8$ years & $1.07(0.91-1.25)$ & 0.41 & $1.04(0.88-1.23)$ & 0.64 & $1.01(0.85-1.20)$ & 0.87 \\
\hline & Chronic diseas & & & & & & \\
\hline & Absent & 1.00 & & 1.00 & & 1.00 & \\
\hline & Present & $0.84(0.71-1.00)$ & 0.05 & $0.84(0.70-1.00)$ & 0.06 & $0.89(0.73-1.07)$ & 0.23 \\
\hline \multirow{6}{*}{$3 r d$} & Smoking & & & & & & \\
\hline & No & 1.00 & & 1.00 & & 1.00 & \\
\hline & Yes & $0.99(0.83-1.18)$ & 0.97 & $0.99(0.83-1.18)$ & 0.98 & $0.96(0.79-1.17)$ & 0.75 \\
\hline & Access to oral & & & & & & \\
\hline & Yes & 1.00 & & 1.00 & & 1.00 & \\
\hline & No & $1.01(0.87-1.18)$ & 0.83 & $1.01(0.87-1.18)$ & 0.83 & $1.17(1.00-1.37)$ & 0.05 \\
\hline \multirow{9}{*}{4 th } & Uses upper der & & & & & & \\
\hline & Yes & 1.00 & & 1.00 & & 1.00 & \\
\hline & No & $0.92(0.79-1.07)$ & 0.28 & $1.08(0.88-1.33)$ & 0.44 & $1.10(0.88-1.37)$ & 0.36 \\
\hline & Uses lower den & & & & & & \\
\hline & Yes & 1.00 & & 1.00 & & 1.00 & \\
\hline & No & $0.86(0.72-1.02)$ & 0.09 & $0.92(0.76-1.13)$ & 0.45 & $0.96(0.78-1.19)$ & 0.75 \\
\hline & Number of teet & & & & & & \\
\hline & $>20$ Teeth & 1.00 & & 1.00 & & 1.00 & \\
\hline & $\leq 20$ Teeth & $1.20(1.04-1.40)$ & 0.01 & $1.23(1.01-1.51)$ & 0.03 & $1.16(0.93-1.45)$ & 0.16 \\
\hline
\end{tabular}

Crude PR: Crude prevalence ratio; ${ }^{*}$ Adjusted PR: Prevalence ratio adjusted for variables from the same block; ${ }^{* *}$ Adjusted PR: Prevalence ratio adjusted for variables from previous blocks.

with the impact on the OHRQoL. Only age remained related to the outcome. In the block of primary determinants of oral health (second block), no variables were significantly associated with the OHRQoL outcome, after adjustment for the exogenous variables. For the factors of health behaviors (third block), access to the oral health service in the PHC was the only variable associated with the OHRQoL outcome after adjustment for the variables in the previous hierarchical blocks. The variables of oral health outcomes (fourth block), i.e., the use of upper dental prosthesis, the use of lower dental prosthesis and the number of teeth, were not associated with OHRQoL outcome (Table 3). 


\section{Discussion}

This is one of the first studies to evaluate access to oral health services in the PHC and its relation to OHRQoL. The main findings support the idea that the act of providing effective access to oral health care, in an opportune and timely form, is associated with better OHRQoL. Additionally, the present study provides significant information for a better understanding of oral health in the PHC, and it documents the OHRQoL of users of oral health services in the PHC.

This study considered access to oral health services in the PHC as a health behavior. Some authors propose that access is an indicator of the level of ease or difficulty through which people have access to health services and that the use of services is determined by different factors and is a complex phenomenon in any community. ${ }^{23,24}$ Among the wide array of factors that influence access are the needs and behaviors of individuals when confronted with health issues, the characteristics of the services provided, the financing tools and the resources made available to the population. ${ }^{25}$

For the PHC system, access may be associated with the location of the health unit, schedule availability and days of care provided, as well as the possibility of providing unscheduled appointments and the perception of the population regarding these factors. ${ }^{15}$ Among the different access markers available, the present study used the availability of unscheduled or spontaneous appointments to assess whether the health service was able, from the user's perspective, to address their health service demands.

One of the challenges emphasized in regard to guaranteeing access to services is that, although the expansion of the basic network has contributed to improved geographical accessibility, there is still a disparity among supply, serviceability and demand. ${ }^{26}$ There are studies that address this disparity in the different levels of complexity of the care network. ${ }^{27,28}$ Within the network, the predominating force is the classic model of disease care for spontaneous demands due to the limitations of comprehensive care and the absence of a regionalized reference and counter-reference network. ${ }^{26}$
Regarding oral health, despite its importance in the health of individuals, there is still a significant portion of the Brazilian population that does not have access to oral health services. In Brazil, there are still inequities in the access and use of dental services. ${ }^{29}$ The epidemiological survey on the oral health conditions of the Brazilian population showed that the prevalence of use of dental services through public service was only $38.3 \%$ for the 35-44 age range and $28.9 \%$ for the $65-74$ age range. ${ }^{30}$

Rodrigues and Assis ${ }^{31}$ conducted research on the supply and demand of public health services and stated that uncertainty in access pushes some social groups away from the public health system, and they then opt for other types of care. This same study emphasizes the unsatisfactory supply of oral health services in Brazil, which cannot adequately address a population that has always had dental healthcare access difficulties and the need for at least one oral health team for each family health team.

The World Health Organization affirms that oral health is a crucial part of health, human function and quality of life. ${ }^{32}$ The study by Agostinho et al. ${ }^{33}$ assessed the self-perception of health among primary care service users in Porto Alegre and confirmed that individuals satisfied with their last appointment were more likely to assess their health as good. A different study determined that dental services sought in emergency situations ha d a greater impact on OHRQoL. ${ }^{34}$ The present study expands on the previous finding, suggesting that having access to spontaneous appointments that, in turn, reflect the perceived need for oral health influences OHRQoL. These findings support the idea that people whose demands for oral health care were not addressed by the PHC had a significantly higher prevalence of impacts on the OHRQoL.

Regarding the clinical variables, a limitation of the study is not having performed an oral examination to differentiate the type of dental prosthesis used since the whole interview took place at the user's house, and the patient reported whether they had an upper or lower dental prosthesis. Furthermore, the position of the teeth when counting the number of natural teeth was not taken as a differentiator. This information is relevant, given that the position of the 
lost teeth has a direct influence on the individual's quality of life. ${ }^{35}$

From all factors examined in this study, access to oral health services in the PHC is associated with a variety of challenges and is seen as an important factor given its impact on people's quality of life. ${ }^{31}$ Finally, studies involving the population that uses private services would contribute towards a better understanding of access to dental services and OHRQoL. Another limitation of this study was the use of the question "When your health center is open and you have an issue with your mouth or teeth, is there someone that can see you on the same day?" Choosing the correct measurements has important theoretical and practical implications. Currently, there are no standardized measurements to evaluate access to the public oral health services. The necessities and behaviors of individuals when facing their own health issues, the disparity between the supply of services and the current demand, the insufficient financing tools and the different resources available to access services make this aspect of healthcare relevant and emphasize the need for effective public policies that are capable of regulating and guaranteeing access to PHC services.

\section{Conclusions}

It was evident that there was a greater impact on quality of life when there was a lack of access to oral health services through the PHC. In this study, the definition of access was based on the availability of dental consultations on demand. Studies such as this one measure the quality of the services provided, contribute to PHC service improvement and offer important advantages for the planning and provision of dental services.

\section{Acknowledgements}

This study was financed in part by the Coordenação de Aperfeiçoamento de Pessoal de Nível Superior-Brasil (CAPES) - Finance Code 001.

\section{References}

1. Locker D, Jokovic A. Three-year changes in self-perceived oral health status in an older Canadian population. J Dent Res. 1997 Jun;76(6):1292-7. https://doi.org/10.1177/00220345970760060901

2. Padilha DM, Hilgert JB, Hugo FN, Bós AJ, Ferrucci L. Number of teeth and mortality risk in the Baltimore Longitudinal Study of Aging. J Gerontol A Biol Sci Med Sci. 2008 Jul;63(7):739-44. https://doi.org/10.1093/gerona/63.7.739

3. Martins AM, Barreto SM, Pordeus IA. [Objective and subjective factors related to self-rated oral health among the elderly]. Cad Saude Publica. 2009 Feb;25(2):421-35. Portuguese. https://doi.org/10.1590/S0102-311X2009000200021

4. Slade GD, Spencer AJ. Social impact of oral conditions among older adults. Aust Dent J. 1994 Dec;39(6):358-64. https://doi.org/10.1111/j.1834-7819.1994.tb03106.x

5. Slade GD. Derivation and validation of a short-form oral health impact profile. Community Dent Oral Epidemiol. 1997 Aug;25(4):284-90. https://doi.org/10.1111/j.1600-0528.1997.tb00941.x

6. Goulart MA, Condessa AM, Hilgert JB, Hugo FN, Celeste RK. Concerns about dental aesthetics are associated with oral health related quality of life in Southern Brazilian adults. Cien Saude Colet. 2018 Nov;23(11):3957-64. https://doi.org/10.1590/1413-812320182311.24172016

7. Oliveira EJ, Rocha VF, Nogueira DA, Pereira AA. Quality of life and oral health among hypertensive and diabetic people in a Brazilian Southeastern city. Cien Saude Colet. 2018 Mar;23(3):763-72. https://doi.org/10.1590/1413-81232018233.00752016

8. Ha JE, Heo YJ, Jin BH, Paik DI, Bae KH. The impact of the National Denture Service on oral health-related quality of life among poor elders. J Oral Rehabil. 2012 Aug;39(8):600-7. https://doi.org/10.1111/j.1365-2842.2012.02296.x

9. dos Santos CM, Martins AB, de Marchi RJ, Hilgert JB, Hugo FN, Padilha DM. Assessing changes in oral healthrelated quality of life and its factors in community-dwelling older Brazilians. Gerodontology. 2013 Sep;30(3):176-86. https://doi.org/10.1111/j.1741-2358.2012.00656.x

10. Weldring T, Smith SM. Patient-Reported Outcomes (PROs) and Patient-Reported Outcome Measures (PROMs). Health Serv Insights. 2013 Aug;6(8):61-8. https://doi.org/10.4137/HSI.S11093

11. Jokstad A. Patient-reported outcomes (PROs) versus patient-reported outcome measures (PROMs)-Is there a difference? Clin Exp Dent Res. 2018 Jun;4(3):61-2. https://doi.org/10.1002/cre2.112 
12. Macinko J, Guanais FC, de Fátima M, de Souza M. Evaluation of the impact of the Family Health Program on infant mortality in Brazil, 1990-2002. J Epidemiol Community Health. 2006 Jan;60(1):13-9. https://doi.org/10.1136/jech.2005.038323

13. Onocko-Campos RT, Campos GW, Ferrer AL, Corrêa CR, Madureira PR, Gama CA, et al. [Evaluation of innovative strategies in the organization of Primary Health Care]. Rev Saude Publica. 2011 Dec;46(1):43-50. Portuguese. https://doi.org/10.1590/S0034-89102011005000083

14. Assis MM, de Jesus WL. [Access to health services: approaches, concepts, policies and analysis model]. Cien Saude Colet. 2012 Nov;17(11):2865-75. Portuguese. https://doi.org/10.1590/S1413-81232012001100002

15. Starfield B. Atenção primária: equilíbrio entre necessidades de saúde, serviços e tecnologia. Brasília, DF: Unesco; 2002.

16. Ascef BO, Haddad JPA, Álvares J, Guerra AA, Costa EA, Acurcio FA, et al. Qualidade de vida relacionada à saúde dos usuários da atenção primária no Brasil. Rev Saude Publica. 2017;51(suppl 2):22s. https://doi.org/10.11606/s1518-8787.2017051007134

17. Teixeira MF, Martins AB, Celeste RK, Hugo FN, Hilgert JB. Associação entre resiliência e qualidade de vida relacionada à saúde bucal em idosos. Rev Bras Epid. 2015 Mar;18(1):220-33. https://doi.org/10.1590/1980-5497201500010017

18. Cancio V, Faker K, Bendo CB, Paiva SM, Tostes MA. Individuals with special needs and their families' oral health-related quality of life. Braz Oral Res. 2018 May;32(0):e39. https://doi.org/10.1590/1807-3107bor-2018.vol32.0039

19. Musskopf ML, Milanesi FC, Rocha JM, Fiorini T, Moreira CH, Susin C, et al. Oral health related quality of life among pregnant women: a randomized controlled trial. Braz Oral Res. 2018;32:e002. https://doi.org/10.1590/1807-3107bor-2018.vol32.0002

20. Cardozo DD. Validação e aplicação PCATool-SB para avaliação da qualidade da Atenção Primária à Saúde Bucal : versão usuários. Porto Alegre: Universidade Federal do Rio Grande do Sul; 2015 [cited 2018 Set 17]. Available from: http://hdl.handle.net/10183/133142

21. Ministério da Saúde (BR). Secretaria da Atenção em Saúde. Departamento de Atenção Básica. Manual do Instrumento de avaliação da atenção primária à saúde: primary care assessment tool PCATool -Brasil. Brasília DF: Ministério da Saúde; 2010.

22. Andersen RM, Davidson PL. Ethnicity, aging, and oral health outcomes: a conceptual framework. Adv Dent Res. 1997 May;11(2):203-9. https://doi.org/10.1177/08959374970110020201

23. Donabedian A. An introduction to quality assurance in health care. Oxford: Oxford University Press; 2002.

24. Mendoza-Sassi R, Béria JU. [Health services utilization: a systematic review of related factors]. Cad Saude Publica. 2001 Jul-Aug;17(4):819-32. Spanish. https://doi.org/10.1590/S0102-311X2001000400016

25. Travassos C, Viacava F, Fernandes C, Almeida CM. Desigualdades geográficas e sociais na utilização de serviços de saúde no Brasil. Cien Saude Colet. 2000;5(1):133-49. https://doi.org/10.1590/S1413-81232000000100012

26. Souza EC, Vilar RL, Rocha N, Costa UA, Medeiros RP. Acesso e acolhimento na atenção básica: uma análise da percepção dos usuários e profissionais. Cad Saude Publica. 2008;24(1 suppl 1):100-10. https://doi.org/10.1590/S0102-311X2008001300015

27. O'Donnell O. Access to health care in developing countries: breaking down demand side barriers. Cad Saude Publica. 2007 Dec;23(12):2820-34. https://doi.org/10.1590/S0102-311X2007001200003

28. Castro MS, Travassos C, Carvalho MS. [Impact of health services delivery on hospital admission utilization in Brazil]. Rev Saude Publica. 2005 Apr;39(2):277-84. Portuguese. https://doi.org/10.1590/S0034-89102005000200020

29. Barros DJ, Bertoldi DA. Desigualdade na utilização e no acesso a serviços odontológicos: uma avaliação em nível nacional. Cien Saude Colet. 2002;7(4):709-17. https://doi.org/10.1590/S1413-81232002000400008

30. Ministério da Saúde (BR). Projeto SB Brasil 2010: Pesquisa Nacional de Saúde Bucal: resultados principais. Brasília, DF: Ministério da Saúde; 2012.

31. Rodrigues AA, Assis MM. Oferta e demanda na atenção à saúde bucal: o processo de trabalho no Programa Saúde da Família em Alagoinhas - Bahia. Rev Baiana Saude Publica. 2005;29(2):273-85.

32. Petersen PE. The World Oral Health Report 2003: continuous improvement of oral health in the 21 st century-the approach of the WHO Global Oral Health Programme. Community Dent Oral Epidemiol. 2003 Dec;31(s1 Suppl 1):3-23. https://doi.org/10.1046/j..2003.com122.x

33. Agostinho MR, Oliveira MC, Pinto ME, Balardin GU, Harzheim E. Autopercepção da saúde entre usuários da Atenção Primária em Porto Alegre, RS. Rev Bras Med Fam Comunidade. 2010 Jan/Dec;5(17):9-15. https://doi.org/10.5712/rbmfc5(17)175.

34. Chapelin CC, Barcellos LA, Miotto MHB. [Dental treatment effectivenessn and life quality impact reduction]. Brazilian J Health Res. 2008;10(2):46-5. Portuguese. https://doi.org/10.21722/rbps.v0i0.479

35. Batista MJ, Lawrence HP, de Sousa ML. Impact of tooth loss related to number and position on oral health quality of life among adults. Health Qual Life Outcomes. 2014 Nov;12(1):165. https://doi.org/10.1186/s12955-014-0165-5 